\title{
TOILETS, Tears AND Transcendence: The Postmodern (Dis-)Placement of, and in, Two Water-Based Examples of Australian Sound Art
}

\author{
Transforming Cultures eJournal, \\ Vol. 4 No 1, April 2009 \\ http://epress.lib.uts.edu.au/journals/TfC
}

\section{Linda Kouvaras ${ }^{1}$}

\begin{abstract}
Water has enjoyed an enduring place as subject matter in western musical works for centuries. And what Douglas Kahn calls "discursive" water has streamed in 'traditional' musical works from Handel's Water Music from 1717 through Romanticism, "albeit in the harmonic gushes that repulsed Cage". In the 'experimental' genres, the early to middle parts of the twentieth century were splattered by various engagements with water and sound, with Percy Grainger's Free Music innovations sparked by gazing at the waves in the Victorian waters of his childhood from as far back as the late nineteenth century. Water in Surrealist art of the mid-twentieth century often featured live women inhabiting large fish-tank/window displays of sound and water - but their own voices were silent. Kahn wonders whether water for the Surrealist men represented "the vaunted maternal voice proffered in certain psychoanalytic scenarios". But as Kahn also comments, "since the early 1960s, innumerable artists have combined sound, fluidity and water in every way imaginable". Two examples of postmodern Sound Art, "Tears", from Passion (1998), by Andrée Greenwell and The Gordon Assumption (2004) by Wax Sound Media artists David Chesworth and Sonia Leber, have traversed a sizable slab of historico-cultural ground in their use of water (via toilets!) as a major component since midcentury modernism. Through select psychoanalytic theories, it is fascinating to witness how they grapple with the themes of water, woman's voice and transcendence - "discursively", with a re-examination of the notions and possibilities of "harmonic gushes", as well as using modernist-based technology.
\end{abstract}

\section{Introduction}

I examine here two contemporary Australian Sound-Art works, The Gordon Assumption by Sonia Leber and David Chesworth (2004), a sound installation, and "Tears", the final movement of Andrée Greenwell's Passion (1993). They each feature emotion-inflected women's voices and connote water as a facet of their subject matter, an aspect of which

\footnotetext{
${ }^{1}$ Linda Kouvaras is a senior lecturer in Music at the University of Melbourne.
} 
includes toilets, and through which the works present a postmodern take on transcendence.

Water has enjoyed an enduring place as subject matter in Western musical works for aeons. It has been partnered with sound in observational acoustics stemming from ancient times through to Chaucer and Helmholtz and beyond, when the noise of a stone smacking onto water produced a visual correspondence, which was in turn figured back onto the sound waves' invisible movements (Kahn 1999: 246). And what Douglas Kahn calls "discursive" water has streamed in 'traditional' musical works from Handel's Water Music from 1717 through Romanticism, "albeit in the harmonic gushes that repulsed Cage" (1999: 246).

In the 'experimental' genres, the early to middle parts of the twentieth century were splattered by various engagements with water and sound, with Percy Grainger's Free Music innovations sparked by gazing at the waves in the Victorian waters of his childhood from as far back as the late nineteenth century. ${ }^{2}$ In fact, as Kahn comments,

since the early 1960s, innumerable artists have combined sound, fluidity and water in every way imaginable, and they have done so concurrently with the rise of environmentalism, which politicised the naturalism and poetics of materiality already practiced within the arts, and the unfettering of the body. Many of these practices have become infused with sonic flows of semiosis that acknowledge that water is no longer an inert element (1999: 288).

For Australia, water is emphatically not an "inert element": it is, rather, a highly emotively volatile element and has featured in countless Australian Western artworks across all genres since Settlement — with preoccupations ranging from the early

\footnotetext{
${ }^{2}$ Water-with-sound endeavours continued on the part of such innovators as Futurist Luigi Russolo with his gurgler from the second decade of the twentieth century, Henry Cowell and his " 8 Rice Bowls" tuned to no definite pitch using water for Ostinato Pianissimo (for Percussion Band) (1934) (Kahn 1999: 248). Eric Satie's wet percussion (that is, percussion tuned by water) in Parade (1918), Harold Davidson with his water-tuned musical tumblers early 1930s (ibid. 249). William Russel's, Harry Partch's and Ray Green's respective water-tuned musical tumblers and bottles works of the early 1930s, John Cage, whose first official use of water was in his collaboration with Lou Harrison, Double Music (1941) which required a Chinese gong being raised or lowered into a tub of water after striking it (ibid. 249). Cage's first mention of using water in music was in his "The Future of Music Credo" (1937), where the sounds or rain could be "captured and controlled" by film phonographs etc (Cage, 1937/2004, cited in Kahn 1999:249).

There are also George Brecht's and Fluxus's respective late 1950s-early 1960s dripping-works; in Yoko Ono's and Mieko Shiomi's early 1960s water-themed pieces; and in Annea Lockwood's river recordings from 1966 onwards. (See, for example, Kahn 1999). Lockwood's River Archive wants to record every river in the world (ibid. 288).
} 
explorers dying from the lack of it to present-day drought affecting so much of the country, and flooding other parts. ${ }^{3}$

But the two Sound-Art works I wish to address here, The Gordon Assumption and "Tears", do not tap into this pocket of the Australian psyche, the one shaped by these types of watery preoccupations. Rather than any geological-environmental focus, they address certain bodily iterations of liquid exudations within a musical context, presented by female voices: The Gordon Assumption was 'performed' at a disused toilet block, while "Tears" uses the flushing of a toilet as part of its sound composition. To situate the works, I need to return to the evolution of works-on-water throughout the twentieth century, and thence to tease out the other associations conjured by the works, namely, psychoanalytic associations that are mobilised by the displacement of their subject matter and musical components.

\section{Accounts of psychoanalytic associations in woman's voice}

Water's featuring in Surrealist art, and that of its forefather Raymond Roussel of the mid-twentieth century, "remarkably consistently" portrayed live women "immersed in a concurrence of sound and water — in window displays, no less" (Kahn 1999: 253-54).

[W] hen we move to the representation of women's voices in these three instances of immersion [by Roussel, Breton, and Aragon], what we find is that the voices are absent, supplanted by sounds as if in song or silent altogether, with sounds accompanying a dance of their presence, if not their actions. These women, in other words, have had their say in the matter dramatically reduced, both as mental and physical creatures, as occurs in many Surrealist texts and images. They are creatures after all, contained in a water in which creatures live,

\footnotetext{
${ }^{3}$ The environmentalism noted by Kahn (above) finds its application in Australia in (at time of writing, 1 May) the most recent episode of the ABC TV series, Catalyst, which investigates the fire/water synergy in the much-threatened Murray-Darling River (Willis 2008), as does the latest presentation (4 May) of Channel Nine's Sixty Minutes (Wooley 2008). Water's precariousness is of course not only felt in Australia: recent acknowledgement of global warming calls attention to it across the world. But among western-culture countries, we are highly branded by weather extremes and their consequences. Indeed, so significant is water for the national consciousness that historian and broadcaster, Michael Cathcart, believes that how Australians live and think has been shaped by water — "or rather by the lack of it", as reported in an article on him entitled "Shaping and Shaped by a Dry Heart" (Smith 2008). He paints a picture of the dry interior coming into the national psyche "as a 'troubling desolate silence' with aridity at its heart. Because of that, during the nineteenth century, an awareness of lethargy and death arose that seemed to capture the spirit of the "silent land" (Smith 2008). He accounts for the mythologising of Burke and Wills as being due to the "arid heart" having taken their lives: "They were received into the mystery that lies at the heart of Australia, and we became fascinated by that" (quoted in Smith 2008).
} 
a water that man can live beside or on or gaze on, especially when the side of the sea is exposed as a fish tank posing as a window display (ibid. 257).

Kahn wonders whether the Surrealist men here

were gazing on and longing for their own former intrauterine immersion, their desire manifesting itself as nostalgia? [...] Intrauterine sound itself [...] would relate to the vaunted maternal voice proffered in certain psychoanalytic scenarios. The sound would be a hydrologically filtered mother's voice promising the bliss of undifferentiation (Kahn 1999: 256-7).

Kahn is referring here, I would suggest, to such Kristevan-derived theories (1984: 1980) as those which have explored poetic language, abjection and the semiotic chora, as part of what she defines as an integral part of personality formation at the pre-lingual stage of infant development. Kristeva's ideas have been addressed by Kaja Silverman, whose critique has especial significance for the Australian works I wish to examine, both of which feature women's voices (many, for the Chesworth-Leber, one for the Greenwell). The voices in The Gordon Assumption sing on 'ah', the single voice in "Tears" sings 'nonsense' words: in each work, we are invited to focus on the female voice(s), rather than on any sung verbal meaning. Silverman discusses the "primal figure" (Dunn and Jones 1994: 11) of female vocality: ${ }^{4}$ primal because, according to what Silverman has called "a powerful cultural fantasy", the maternal voice is the "first voice of love" (1988: 72). ${ }^{5}$ Reconstruction of this irrevocable infantile moment gives rise, according to Silverman, "to two opposing 'fantasies' of the female voice: the positive fantasy of blissful union, and the negative fantasy of entrapment" (1988: 72). ${ }^{6}$ "This potent dream of maternal presence - a presence that is embodied, literally, in the 'bath of sounds' created by the mother's soothing, singing voice - has resonated in Western literature and music for centuries" (1988: 72). As Silverman points out, both these negative and positive versions "equate the maternal voice with pure sonorousness" (Jones 1994: 48) (which, at the very least, distorts the mother's real role as linguistic initiator to the child). ${ }^{7}$

\footnotetext{
${ }^{4}$ Also see Flinn 1986 and Flinn 1992 for further discussions of the psychoanalytic construction of the maternal voice.

5 The phrase 'first voice of love' is Hélène Cixous' (Cixous and Clément 1986: 93).

${ }^{6}$ For Silverman's discussion of positive and negative fantasies of the maternal voice, see Silverman 1988:72-100, cited in Dunn and Jones 1994: 4.

${ }^{7}$ Silverman observes that the phallic model fails to take into account the crucial role that the mother plays in the child's early history of subjectivity. "Not only is her face the visual mirror in which the child first sees itself, but her voice is the acoustic mirror in which it first hears itself" (Silverman 1988:150). Indeed,
} 
Ideas of Kristevan-informed psychoanalysis, the female voice and "pure sonorousness" are also explored in Michel Poizat's book, The Angel's Cry: Beyond the Pleasure Principle in Opera (1992). ${ }^{8}$ The "pure cry", the inarticulate explosion most absolutely represented at the death of Berg's Lulu, is the apex of operatic expression for Poizat. At a remove from both notated music and from verbal text, this vocality is a sliver of unimpeded communication, a vocality imbued with base emotions that transcend language's mediation. Its power derives from psychoanalytic accounts of early childhood, when the infant's inarticulate cry is answered by the mother. The cry's significance is due to its complete lack of signification; it is an unadulterated voiced manifestation of the child's discomfort rather than of any precise need. This extreme of emotion is only possible prior to the acquisition of language, which will act to sift all desires through societal structures. Just as Lulu's cry is too keen, too heightened, to be enclosed by musical notation, the child's cry is too raw in the power of its exigency to even be imaginable in words. Because of this, that first cry can never be recovered: "as soon as it is interpreted and elicits a reaction [from the mother], its original 'purity' is lost forever, as it is now caught up within a system of signification" (Poizat 1992: 101). To put this another way, all cries after this moment will be specific in their asking, and will therefore no longer have the sensuous and purposeless vocality of the first utterance. The pursuit to recapture the cry is, for Poizat, the basis of the operaphile's obsession, most intensely, of the pleasure - or, more accurately, the jouissance — that resides in great singers and especially their highest notes. This point will be shown to have acute resonance for The Gordon Assumption in particular.

Mary Ann Smart encapsulates Poizat's arguments:

The power of the cry is nearly all-encompassing for Poizat. It is also the point at which the composer's impulse and the listener's response meet, in a shared rejection of the ordered systems of music and language. Just as composer and singer embrace pure vocality at the moment of the cry, tears are the only adequate response on hearing the cry, as the listener him[/her]self is robbed of speech and language (1993: 117).

Tears imagery proliferates throughout The Angel's Cry. The opera house is a matchless world where all, even men, may weep freely, without feeling the need to suppress their

\footnotetext{
the mother's voice is notoriously absent in psychoanalytic tales. I have also discussed these critiques in another context (Kouvaras 2002).

${ }^{8}$ I wish to thank Jennie Shaw for alerting me to Poizat's book.
} 
tears. The unfolding of opera's narratives is wrought by a desire to hear high voices at extremes of expression.

Catherine Clément (1989) has drawn our attention to the fact that a staggering number of these plots are distinguished by heroine death (particularly in nineteenth-century opera). Poizat sees a primary reason for this as opera's aesthetic, which sees all aspects of opera as determined by the search for sensual moments of vocal pleasure:

It is not because the dramatic logic of the libretto has led the female character to her death that she cries out at that moment; it is because the logic of vocal jouissance is at work and is driving the cry that the dramatic conditions necessary for its occurrence are created, demanding a death (1992: 145).

Clément's (1989) claim, however, is that the deaths are necessary for narrative closure: the female characters, being potentially subversive 'Other', must be annihilated. Either way, the plight of the women is, to say the least, an unhappy one, just as it is for the silent Surrealist women subjects in their watery prisons.

\section{Mid-century modernist, emotion-free, watery forays}

I want now to jump across genres again, back to Cage's experimentalist innovations in water sounds in the 1930s and 1940s, to develop my next area of discussion. Rather than being the purpose of the artwork to move the listener as in traditional opera, emotion in early-to-mid-twentieth century is confined to the nascent modernist sense of excitement and exhilaration on the part of the creators at being able to work with water and sound, to control its place in their art-making (albeit, of course, in a purposefully random, experimentalist way). The achievement here is the very first-principles basis for engaging with water in soundworks, appreciating the aesthetic potential of an unusual sound source relative to traditional Western art-music, and celebrating the passing of the mid-twentieth-century moment of, as Kahn puts it, "water, water everywhere in program music but nobody [getting] wet": now, Cage was able to exclaim about his Water Music (1952) in a letter to Slonimsky, "unlike Handel's, it really splashes" (cited in Kahn 1999: 245). ${ }^{9}$

\footnotetext{
9 "Water was no longer contained in the instrument, but now the instrument was contained in the water" (Kahn 1999: 250). Similarly, George Brecht delighted in the fact that "out of all the people who heard water dripping, I'm the first person to make a score out of it, so in a way the score calls attention to the
} 
Of course, it was not only Cage who abhorred the "harmonic gushes" (Kahn 1999:246, quoted above) and expressions of emotions in general through music. Modernists from both experimentalism and 'academic' high modernism (or, as coined in New York, 'uptown' high modernist, score-based works and 'downtown' experimentalist ex-scorebased works) purposefully shunned emotive connotations in their works. One of the most interesting points of departure for me at the historical juncture of modernism and postmodernism from about 1968 onwards is postmodernism's willingness to re-visit the emotional realm: not, it must be stressed, in a wholesale return to Wagnerian, unproblematised, heart-on-sleeve harmonic effusiveness but in an ironic, detached manner with aesthetic 'investigation' as one of its key concerns; this is a point of focus for "tears". The two works which I present can be perceived to deal with the place of water in music and woman's voice through a postmodernist prism, raising issues of expressiveness, psychoanalysis, and transcendence.

\section{The Gordon Assumption: critiquing the "bliss of undifferentiation"}

The Gordon Assumption (2004) is an audio-visual collaboration of the duo 'Sonia Leber and David Chesworth', comprising UK-born Australian-based Sound Artist David Chesworth (b. 1958) and Australian Sound and Visual Artist Sonia Leber (Chesworth and Leber 2004). Chesworth declares:

From very early on I was always interested in problematising the engagement between the performer and the audience that is to say, making the audience slightly unsure of how they relate to the music [...] in order to make them think about what the piece is doing and about their relationship to the work (Chesworth 2007).

The Gordon Assumption is a work which certainly enacts this aim. ${ }^{10}$ It was a Sound Installation in the Subterranean Toilets, Gordon Reserve at Parliament Station, Melbourne, as part of the 2004 Melbourne International Arts Festival. The reference is

\footnotetext{
fact that water dripping can be very beautiful - many people find a dripping faucet very annoying, they get very nervous" (cited ibid. 282). For these people, the sound of water is out of place in a musical or artistic context.

${ }^{10}$ While the work was only 'live' during the Festival, a sizable portion of it is still accessible online (Chesworth and Leber 2004).
} 
to the bodily Assumption of Mary (her physical ascent into Heaven). ${ }^{11}$ Leber and Chesworth's program note reads:

An incessant outpouring of female voices lures passers-by down the stairwell to the cave-like subterranean toilets. At the lower gates, they are confronted with an asynchronous chorus of female voices in infinitely rising pitch. The voices gather and thicken without respite, in upwards glissandi, constantly trailing upwards. Behind the locked gates, the luminous green chamber beckons as a single vertical slit of brilliant white light slowly scans the surfaces.

The subterranean setting reveals itself as a point of rupture in Melbourne's everyday cityscape of workers, commuters and public transport. The voices recall the mythologies and mysteries of voices heard in caves, where the voices of spirits, sibyls and oracles are believed to announce predictions and warnings from the mouth of a cave. Above ground in Gordon Reserve, new arrivals gather in apprehensive huddles, prior to making their cautious descent into the upward trails of female voices (Leber and Chesworth 2004).

The Gordon Assumption engages in an acutely postmodern fashion with such notions, presenting them very tongue-in-cheek. The artists enjoyed the slight perturbation on the part of passers-by for these "trapped women": Chesworth reports, "people were concerned for the wellbeing of the ladies in the toilet. Did they get tired? When did they eat? They thought there were 100 women down there" (in Scott-Norman 2007). On the one hand we have a 'pure' instance of high female voice "detached from signification", a stark "rejection of the ordered systems of music and language" (Smart 1993: 117, quoted above): there is no 'music', per se, and no 'text'. There is just the ascending, random glissandi of the soprano voices. But the jouissance of experiencing the high voices is offset by the 'discomfort' in the projected interpretation of the women's predicament and in the spectators' own unsureness of what to do about these screams. This is arguably counter-balanced by the conflicting, seductive, mythologised lure of sirens to depths unknown and potentially dangerous, indeed "entrapping". And, from yet another perspective, unease is conjured, possibly, by the inopportuneness of being able to surrender to the psychoanalytic urge described by Poizat to tear-up - in a public space, not to mention the squeamishness associated with the realm of the toilet. The audience can find no place of comfort in which to 'put' their emotional reaction(s).

${ }^{11}$ But as Peter King in the Program catalogue avers, "the 'assuming' is ongoing and provisional: a thickening exhumation of protocols of [un?]imaginably primal music and sound: upward glissandi, Shepard's Tones...No madrigals for Mary" (King 2004). 
These voices that one might normally expect to hear in an operatic performance are utterly out of context, displaced, in this disused, non-functioning toilet block beside a major public transport node. They perform a feminist-postmodern answer/antidote to the Surrealists' immersing of the women in water and giving them no 'voice', while they turn on its head the psychoanalytic "positive fantasy of blissful union, and the negative fantasy of entrapment" (Silverman 1988: 72, quoted above): rather than the subject, in other words, the fantasist, who desires to return to pre-Symbolic - prelinguistic - "entrapped" infancy, the Gordon Assumption women themselves are the ones entrapped! Similarly, the "'bath of sounds' created by the mother's soothing, singing voice" which has "resonated in Western literature and music for centuries" (ibid. 72) is displaced here with postmodern irony: the "bath" is a disused toilet. There is no lurid gazing on the part of the spectators at any female forms: the women's voices lure the audience down into their space, their false-promise womb-space - there are no wombs attached to these recorded voices as they inexorably rise and rise and are unassailably heard.

Chesworth's remarks, "the beauty of working with sound is [that] it's very focusing and personal - people think that it's just for them. And you can't turn away from sound like you can from a painting" (in Scott-Norman 2007), have pointed resonance in this work with the psychoanalytic dimension associated with woman's voice. The Gordon Assumption critiques the psychoanalytic promise through the mother's voice of the "bliss of undifferentiation" (Kahn 1999: 256-7, quoted above) and the quest to "recover the first cry" (Poizat 1992: 101, quoted above). We do not know why the Assumption voices are pushed to extremes of expression, unlike the case of operatic plots that demand such heights. We are left only with the sign of the extreme, the trace of the operatic heroines pushed to their death by our jouissant desire. The transcendent moment is fixed in time: the glissandi actually go nowhere, to no other place (defined musical note), nor do they start from anywhere, from any particular place (defined musical note); the emotionally charged, "gushing" moment is all there is. Left only to contemplate what might be the cause, and the fact that we expect there to be such a cause, the audience is in a position to apprehend the situation for these women from the toilets who burst the seams of their confinement, operating outside the boundaries of the ersatz-uterine wall, heard where they should not be, transgressing place. 


\section{"Tears": a postmodern Sound-Art expression of grief}

The postmodern expression of water in music finds its way into "Tears", the final movement of Australian composer Andrée Greenwell's (b. 1964) Passion (1993) (for soprano, tenor, female voice, trumpet, baroque organ and cello; "Tears" uses voice, electronics, a pre-recorded cello track and baroque organ). ${ }^{12}$ Greenwell's engagement here is with the Passion story, another religio-transcendent-themed catalyst, whose emotional impact has been elaborated, over the centuries, in Western-music religious works. "Tears" engages acutely — but with critical distance — with feeling in music, distilling an essence of lamentation: namely, the natural, bodily noise of grief, and strongly associated with the Passion story. Here, the mezzo soprano voice range does not reach into the "pure cry" coloratura heights, but, like The Gordon Assumption, which uses no distinguishable words, there is avoidance of signification: Greenwell sings made-up, quasi-ancient words (Kouvaras 1998).

As a large-scale postmodern grappling with emotional responses to music, Greenwell turns the song into a sonic code, just as do 'Sonia Leber and David Chesworth' with their jouissant chorus. The first third of this track comprises the sounding of what is usually silent: tears - here magnified, into a New-Ageian, veritable Flood of tears, pouring forth — wept over the ages, but obviously sampled, treated, unnatural; produced by the recording of the flushing of a toilet (Kouvaras 1998) they have paradoxically become an acculturated event here. Creating a further postmodern tension between engaging with and distancing from her material, Greenwell employs sampled sobbing (her own) on "Tears" (Kouvaras 1998). The sobbing borders the guttural emission/voice divide — at what could be called the pre-"pure" cry moment, comprised only of sharp, gasping intakes of breath treated in such a way that one can indeed recognise it as sobbing - and woman's, not infant's, sobbing at that. But the technology makes for examination of the sobbing rather than wholesale acceptance of it. The looped repetition renders the sobbing mantra-like, beyond emotion. The listener can simply concentrate on it and observe it, rather than empathise with it. There is no pretence of 'naturalness': the listener is aware of the tape-loop and cannot engage on a purely unmediated emotional level. Greenwell's postmodern treatment of, and choice of source for, the sounds of grief, points out the contrivances.

\footnotetext{
12 Passion was commissioned by the Sydney Front Theatre Company, and the disc was launched by Winsome McCaughey at the Composing Women's Festival at Melbourne's Malthouse Theatre complex in June 1994.
} 
The voice in "Tears" emerges from this flood, accompanied by neo-tonal 'music', jarring with high modernism's (both 'up'- and 'downtown') over-riding banishment of tonality and its ideal of a coherent soundworld/emotions. It comprises mostly triadic harmonies, although the postmodern progressions are not functional: $\mathrm{g} \#$ min to G Maj; E Maj; b min; g min (with the note C\# appearing on the final beat in the voice, making a g dim triad); D Maj; then the cycle repeats, ending up in the 'tonic' of g\# min only to elide subtly into E Maj with a shift in the inner voice of the organ from D\# to E. The melodic and harmonic rhythm are irregular, with changes occurring not-quitepredictably, within an overall basic slow $4 / 4$ meter, replete with an extended passage for a vocal semi-cadenza on the second cycle over the G Maj section - giving an overall quasi-improvisatory effect. The minor/major mixture of the harmonic progression is, appositely, highly affective, and the intimacy of one voice and only organ accompaniment in this movement adds to the personalised, poignant, subjective effect of the movement, much as an aria from Bach's St Matthew Passion does (the baroque organ here making this association pointed).

Also featured are glissandi, as in The Gordon Assumption. But here they are (post-Bach) Sculthorpian 'seagull/whale' effects, produced by rapid, irregular downward-moving glissandi on the cello, sounding in this context as though they, too, are in grief, which in tandem with the harmonic treatment, gives way to suggestions of flight and transcendence. But these, like the sobbing and the tears-gush, are contrived, recorded and treated with echo and overlap, and in turn point to the similarly manipulative quality of (the) affective music. Aesthetic 'transportation' or religious 'transcendence' mixes here with the foregrounding of artifice - we feel carried away by the flood of water, of emotion... we are helpless in its wake. The connotation of tears, the sobbing sounds, voices, even the whale/seagull noises, naturally evoke the bodily. But the distorted treatment of the 'natural' sobbing noises - using amplification, echo, overlapping and overlayering, not to mention the extreme length of the duration of the two sounds - gives rise to a sense of disembodiment, a postmodern departure from the 'natural'. The sounds in "Tears" refer to their own production rather than signifying proceedings or conduct of which they are the sounding result.

One reading from this surreal flood could be an invitation to focus on the way Western music ("harmonic gushes") has been used throughout the centuries, to evoke and 
manipulate emotional responses, perhaps to invite scepticism of the truthfulness of emotion paraded in the Passion tale and indeed other socio-cultural contexts. This has perhaps been never more pertinent a consideration than at the present time: interminably advancing computer technology has provided the modernist-dream means at an instant to catch, control and contrive virtually any sound imaginable. But the postmodern sound manipulation in “Tears” and The Gordon Assumption is a far cry on from modernism's early joy in primitive recording ventures and watery soundscapes.

\section{Conclusion: Sound Art's postmodern displaced "transcendence"}

Despite the movement of the attendant glissandi in each of the Australian works discussed here (rising voices in the 'Sonia Leber and David Chesworth' work, descending cello in the Greenwell), emotion is a frozen element, going no place, repeating over and over like the crying-out of women's voices over the aeons that should have been heard but were not — and forming an antidote to modernism's squeamishness about emotion. Performing a latter-day, newly aestheticised take on Duchamp's Fountain of 1917 which made a urinal a piece of art just by calling it such, the works reassert the notion that art can take place anywhere now, and that art has an under-belly: the ethereal voices and the transcendent religious grief-sobbing are firmly conjoined to their bodily housing - the most ethereal voice has to have a functioning, toilet-using corporeal reality, a fact not made much of in works from modernist or premodernist eras. But in a sublimely twisted postmodern move, here, with the wonders of technology, this is actually not the case - there are no bodies, the voices actually are ethereal, and the auditor/spectator cannot shut them out. This is palpably unlike the case for the mid-century modernist Surrealists' voiceless women in their watery confines, whose voices never were audible. It is similarly unlike that for the traditional operatic female characters, whose fatalities were pre-ordained - whether due to "the logic of vocal jouissance" (Poizat 1992:145, quoted above) or to the exigency of narrative closure's obliteration of the threatening 'Other' (Clément 1989). The female characters in both instances deserve a meta-cry such as that offered by the Gordon Assumption wailing voices or by the protracted sobbing in "Tears".

These two works thus offer a broader-stance commentary on significant aspects of high art over the past couple of hundred years and experimentalist culture since mid-last 
century. They simultaneously interrogate our collective sense of psychic and bodily place, of inside-ness (ranging from the protected, blissful, watery, foetal environment, to the enclosed, private, watery space of the toilet) and outside-ness (where such spaces are re-positioned and no longer belong to the inner realm), throwing up the issue of inappropriateness (which is essentially, after all, something occurring in the place that it normally should not).

The starkly confronting Gordon Assumption females screaming from the subterranean depths, ${ }^{13}$ the Passion tears-flood produced from the very receptacle for our bodily wastes, are anathema to high art: they show us our base-est selves, and firmly plug for the insertion of the mundane into high art. And in their engagements with music, sound, woman's voice, tears and toilets, the postmodern message, the reality-check, for the psyche - which neither traditional opera nor surrealism nor modernism offer - is this: one can never return to that pre-Symbolic state of infantile bliss: there is no more such transcendent moment to be had. Perhaps, therefore, in a final, sublime postmodernist spiral, the offer here is of the true, postmodern sonic utopia, that is, the place that is no place.

\section{Acknowledgment}

The research for this article was funded by an Australian Research Council Discovery grant.

\section{Bibliography}

Cage, J. (1937/2004) "The Future of Music: Credo", in Christoph Cox and Daniel Warner (eds.) Audio Culture: Readings in Modern Music. New York: Continuum.

Chesworth, D. and Leber, S. (2007) The Gordon Assumption $<$ http://www.waxsm.com.au/gordon.htm>, 15 May, 2008.

(2007) "Works by Wax Sound Media", Institute of Postcolonial Studies Seminar Series. Melbourne.

Cixous, H. and Clément, C. (1986) The Newly Born Woman. Theory and History of Literature: V. 24. Manchester: Manchester University Press.

Clément, C. (1989) Opera, or, the Undoing of Women. Minneapolis: University of Minnesota Press.

\footnotetext{
${ }^{13}$ The Gordon Assumption forms a grander-scale association with the shameful predicament of detainees in our refugee camps, and recently the Austrian "incest victims" in their subterranean prison (Schwab 2008).
} 
Dunn, L.C. and Jones, N.A. (1994) "Introduction", in Leslie C. Dunn and Nancy A. Jones (eds), Embodied Voices: Representing Female Vocality in Western Culture. Eds. New Perspectives in Music History and Criticism. Cambridge: New York, NY, USA: Cambridge University Press, 1994.

Flinn, C. (1986) "The 'Problem' of Femininity in Theories of Film Music", in Screen 27.6: $56-72$.

(1992) Strains of Utopia: Gender, Nostalgia, and Hollywood Film Music. Princeton, N.J.: Princeton University Press.

Greenwell, A. (1993) Passion. Kensington, Vic.: Newmarket.

Jones, N.A. (1994) "Music and the Maternal Voice in Purgatorio Xix", in Leslie C. Dunn and Nancy A. Jones (eds), Embodied Voices: Representing Female Vocality in Western Culture, New Perspectives in Music History and Criticism. Cambridge: New York, NY, USA: Cambridge University Press.

Kahn, D. (1999) Noise, Water, Meat: A History of Sound in the Arts. Cambridge, Mass.: MIT Press.

King, P. (2004) "The Gordon Assumption", Melbourne International Arts Festival, Visual Arts Program Catalogue. Melbourne: MIFA. Cited $<$ http://www.waxsm.com.au/gordon.htm>, 15 May, 2008.

Kouvaras, L. (1998) "Interview with Andrée Greenwell". Melbourne, 24 June.

(2002) 'The Semiotic and the Symbolic in Two Sweets-Smearing Scenes', in Australasian Music Research, No. 6: 65-86.

Kristeva, J. (1984) Revolution in Poetic Language. Tr. Walker, M. New York: Columbia University Press.

(1980) Desire in Language: A Semiotic Approach to Literature and Art. Ed. Roudiez, LS. Tr. Thomas, G, Jardine, A, and Roudiez. LS. Oxford: Blackwell.

Leber, S. and Chesworth, D. (2004) The Gordon Assumption $<$ http://www.waxsm.com.au/gordon.htm>, accessed 15 May, 2008.

Poizat, M. (1992) The Angel's Cry: Beyond the Pleasure Principle in Opera. Trans. Arthur Denner. Ithaca: Cornell University Press.

Schwab, P. (2008) "Austrian Admits Incest", $<$ http://news.iafrica.com/worldnews/759157.htm> 27 July, 2008.

Scott-Norman, F. (2007) "Giving Voice to Their Art", Age 10 August.

Silverman, K. (1988) The Acoustic Mirror: The Female Voice in Psychoanalysis and Cinema. Theories of Representation and Difference. Bloomington: Indiana University Press.

Smart, M.A. (1993) "(Book Review): The Angel's Cry: Beyond the Pleasure Principle in Opera by Michel Poizat." Opera Quarterly 10: 115-19.

Smith, K. (2008) "Shaping and Shaped by a Dry Heart", The University of Melbourne Voice 3.1.

Willis, P. (2008) "Fire and Water (ABC TV, Catalyst)", $<$ http://www.abc.net.au/catalyst/stories/2230299.htm> 4 May 2008.

Wooley, C. (2008) "River's End (Channel Nine, Sixty Minutes)", $<$ http://sixtyminutes.ninemsn.com.au/> 5 May 2008. 